CENDEKIA, Vol. 12. No. 2 Oktober 2018

p-ISSN: 1978-2098; e-ISSN: 2407-8557

Http://cendekia.pusatbahasa.or.id; Email: cendekiaoslo@gmail.com

Center of Language and Cultural Studies, Surakarta, Indonesia

Syarif, Erman. 2018. Dinamika Pembelajaran Geografi di SMAN 9 Takalar Sulawesi Selatan.

Cendekia (2018), 12(2): 75-84. DOI: 10.30957/Cendekia.v12i2.519

\title{
DINAMIKA PEMBELAJARAN GEOGRAFI \\ DI SMAN 9 TAKALAR SULAWESI SELATAN
}

\author{
Erman Syarif \\ Jurusan Geografi, Fakultas Matematika dan Ilmu Pengetahuan Alam \\ Universitas Negeri Makassar \\ Kampus UNM Parang Tambung, Jl. Daeng Tata, Parang Tambung, Makassar, \\ Kota Makassar, Sulawesi Selatan \\ Email: ermansyarif@unm.ac.id
}

\begin{abstract}
The purposes of this study are to identify the dynamics of geography learning in SMAN 9 Takalar, and to describe what factors are to be supporters of the quality of geography learning in SMAN 9 Takalar. This study used qualitative approach involving teachers at SMAN 9 Takalar as informants. The results showed that the dynamics of learning geography are of less conducive in terms a) learners are less involved in the learning process, b) teachers of geography subject facilitate and motivate learners in the learning process at the minimum degree, c) the teachers do not develop models of innovative learning, and d) in the learning process, teachers rely much on teacher centered approach. In addition, factors supporting the quality of learning of geography comprise of: a) teachers and learners collaborate for the achievement of improved learning outcomes, b) multiple sources a reading and video learning about learning models and developed in geography learning have been used, and c) the teacher is able to understand the characteristics of learners by using a learning model in variety and innovative manners.
\end{abstract}

Keywords: Dynamics, Learning Geography, SMAN 9 Takalar

DOI: $10.30957 /$ Cendekia.v12i2.519

\section{PENDAHULUAN}

Proses pembelajaran merupakan hal penting dalam interaksi antara pendidik dan peserta didik. Surakhmad (2000) mengungkapkan bahwa posisi pengajar dan peserta didik memiliki posisi strategis dalam meningkatkan kualitas pembelajaran. Guru harus menguasai keterampilan dalam mengajar untuk meningkatkan kualitas lulusan dan peningkatan mutu pendidikan (Hamzah, 2006). Lebih lanjut Barnawi dan Arifin (2012) menjelaskan bahwa untuk dapat mencapai mutu pendidikan, maka aspek pengetahuan, keterampilan, sikap dan nilai-nilai harus dilaksanakan secara menyeluruh. Oleh karena itu, guru harus mengoptimalkan peranannya dalam proses pembelajaran.

Pengalaman dan pengetahuan peserta didik dibangun melalui interaksi dengan lingkungannya. Marzano (1993) menjelaskan bahwa pembelajaran yang efektif menekankan pada proses belajar secara personal, dimana setiap peserta didik 
CENDEKIA, Vol. 12. No. 2 Oktober 2018

p-ISSN: 1978-2098; e-ISSN: 2407-8557

Http://cendekia.pusatbahasa.or.id; Email: cendekiaoslo@gmail.com

Center of Language and Cultural Studies, Surakarta, Indonesia

Syarif, Erman. 2018. Dinamika Pembelajaran Geografi di SMAN 9 Takalar Sulawesi Selatan.

Cendekia (2018), 12(2): 75-84. DOI: 10.30957/Cendekia.v12i2.519

membangun pengetahuan dan pengalamannya secara personal. Konsep belajar berasal dari bentuk pengetahuan berupa aktivitas kolaboratif, pengalaman kongkrit, reflektif dan interpretatif (Brooks, 1999). Lebih lanjut Trianto (2009) menyatakan bahwa setiap anak memiliki cara tersendiri dalam menginterpretasikan dan beradaptasi dengan lingkungannya. Pendidikan budaya dan karakter bangsa merupakan salah satu upaya untuk mencegah terjadinya degradasi nilai-nilai etika dan moral di kalangan remaja (Syarif, 2016).

Salah satu wahana yang sangat penting untuk meningkatkan sumber daya manusia adalah pendidikan. Gurfan (2011) pendidikan tidak saja sekedar tuntutan namun merupakan suatu kebutuhan pokok dari setiap insan. Sumber daya manusia yang berkualitas akan mampu mengembangkan potensi yang dimiliki untuk kemajuan bangsa dan negara (Hari, 2011). Pendidikan merupakan proses untuk membantu manusia dalam mengembangkan potensi dirinya (Fitri, 2012). Lebih lanjut Syarif (2016) mengungkapkan bahwa kemajuan suatu bangsa tergantung pada bagaimana karakter dan perkembangan intelegensi anak. Salah satu upaya membina dan membangun sumber daya manusia yang berkualitas dan dapat diandalkan adalah melalui pendidikan formal dan pendidikan informal.

Pendidikan formal memiliki peranan yang sangat penting dalam kehidupan manusia. Zaini, dkk (2007) menjelaskan bahwa pendidikan mempunyai peranan yang sangat penting bagi kehidupan manusia untuk mengembangkan potensi yang ada pada diri setiap anak. Pendidikan memberikan peluang untuk mengembangkan potensi diri agar kelak dapat dimanfaatkan untuk kemajuan bangsa dan negara (Ali, 2009). Lembaga pendidikan formal merupakan salah satu tempat dimana siswa mendapatkan ilmu secara formal yang bertujuan memberikan bekal kemampuan dasar, pengetahuan, dan keterampilan dasar pada peserta didik (Hamruni, 2011).

Peningkatan profesionalisme guru perlu ditingkatkan. Menurut Mulyasa (2007), profesionalisme guru di Indonesia masih sangat rendah, hal tersebut disebabkan karena belum adanya perubahan pola mengajar dan sistem konvensional ke sistem kompetensi dan beban kerja guru yang tinggi. Lebih lanjut Dimyati (2013) seorang guru harus terus meningkatkan profesionalismenya melalui keterampilan dalam memperoleh pengetahuan (learning to know), keterampilan dalam pengembangan jati diri (learning to be), keterampilan dalam pelaksanaan tugas-tugas tertentu (learning to do), dan keterampilan untuk dapat hidup berdampingan dengan sesama secara harmonis (learning to live together). Oleh karena itu, guru dituntut untuk memiliki kompetensi profesionalisme.

Geografi merupakan salah satu mata pelajaran yang diajarkan di SMA kelas X, XI, dan XII program IPS. Berdasarkan hasil observasi pada tanggal 11 Januari 2018 di SMA Negeri 9 Takalar menunjukkan: 1) peserta didik memandang geografi sebagai mata pelajaran yang kurang menarik, tidak menyenangkan, monoton, hafalan, dan tidak penting. Akibatnya, hasil UN mata pelajaran geografi tergolong rendah dan lebih dari $65 \%$ kompetensi tidak dikuasai oleh peserta didik, 2) kurangnya inovasi guru dalam menerapkan model-model pembelajaran; 3) kurangnya kreativitas guru dalam 
CENDEKIA, Vol. 12. No. 2 Oktober 2018

p-ISSN: 1978-2098; e-ISSN: 2407-8557

Http://cendekia.pusatbahasa.or.id; Email: cendekiaoslo@gmail.com

Center of Language and Cultural Studies, Surakarta, Indonesia

Syarif, Erman. 2018. Dinamika Pembelajaran Geografi di SMAN 9 Takalar Sulawesi Selatan.

Cendekia (2018), 12(2): 75-84. DOI: 10.30957/Cendekia.v12i2.519

merancang dan melaksanakan proses pembelajaran; dan 4) guru kurang bisa memanfaatkan lingkungan sebagai media dan sumber belajar.

Rendahnya hasil belajar peserta didik merupakan salah satu permasalahan yang dihadapi dalam pembelajaran di sekolah. Slameto (2013) mengungkapkan bahwa prestasi belajar peserta didik dipengaruhi faktor internal (disiplin belajar, kondisi fisiologis/keadaan fisik dari peserta didik, kondisi psikologi/kecerdasan, bakat, minat, motivasi)dan faktor dari eksternal (lingkungan, alat instrument /kurikulum, metode pembelajaran, sarana, fasilitas dan guru/pengajar,serta suasana belajar peserta didik).

Pentingnya keterlibatan secara aktif peserta didik dalam pembelajaran. Moore (2005) mengemukakan seorang guru dituntut untuk merancang pembelajaran yang inovatif dan merangsang keaktifan peserta didik. Slavin (2006) menyatakan agar peserta didik benar-benar memahami dan sanggup menerapkan pengetahuan, mereka harus berupaya menyelesaikan masalah, menemukan sesuatu bagi diri sendiri dan bergumul dengan gagasan-gagasan sendiri. Pandangan dasar pembelajaran kurikulum 2013 ialah pengetahuan berasal dari peserta didik yang aktif mencari, mengolah, mengkonstruksi, serta menggunakan pengetahuan (Kemendikbud, 2013).

Sesuai dengan latar belakang masalah di atas, peneliti merumuskan tujuan penelitian ini untuk:

1) mengidentifikasi dinamika pembelajaran geografi di SMAN 9 Takalar

2) mendeskripsikan faktor-faktor apa yang menjadi pendukung kualitas pembelajaran geografi di SMAN 9 Takalar.

\section{METODE}

Jenis penelitian ini adalah kualitatif dengan menggunakan pendekatan studi kasus. Sumber data adalah informan seperti tampak pada Tabel 1 dan pertanyaan untuk informan disajikan pada Tabel 2. Adapun lolasi penelitian yaitu SMAN 9 Takalar Sulawesi Selatan disajikan pada peta seperti tampak pada gambar 1.

Tabel 1 Taksonomi Informan

\begin{tabular}{lll}
\hline & InformanKunci & InformanPendukung \\
\cline { 2 - 3 } Informan & 1) Peserta didik & 1) Kepala Sekolah \\
& 2) Guru Mata Pelajaran Geografi & 2) Wakasek Kurikulum \\
& 3) Wali Kelas \\
& 4) Guru Mata Pelajaran \\
\end{tabular}

Tabel 2 Pertanyaan yang di ajukan kepada Informan

\begin{tabular}{lll}
\hline No & \multicolumn{1}{c}{ PertanyaanStruktural } & \multicolumn{1}{c}{ Informan } \\
\hline 1 & Dinamika pembelajaran geografi di & Peserta didik, Guru Mata Pelajaran Geografi, \\
& SMA 9 Takalar & $\begin{array}{l}\text { Kepala Sekolah, Wakasek Kurikulum, dan } \\
\text { Wali Kelas }\end{array}$ \\
2 & $\begin{array}{l}\text { Faktor- faktor pendukung kualitas } \\
\text { pembelajaran geografi di SMA 9 } \\
\text { Takalar }\end{array}$ & $\begin{array}{l}\text { Guru Mata Pelajaran Geografi, Kepala } \\
\text { Sekolah, Wakasek Kurikulum, dan Wali Kelas } \\
\text { dan Guru Mata Pelajaran Lain }\end{array}$ \\
\hline
\end{tabular}


CENDEKIA, Vol. 12. No. 2 Oktober 2018

p-ISSN: 1978-2098; e-ISSN: 2407-8557

Http://cendekia.pusatbahasa.or.id; Email: cendekiaoslo@gmail.com

Center of Language and Cultural Studies, Surakarta, Indonesia

Syarif, Erman. 2018. Dinamika Pembelajaran Geografi di SMAN 9 Takalar Sulawesi Selatan.

Cendekia (2018), 12(2): 75-84. DOI: 10.30957/Cendekia.v12i2.519

Lokasi penelitian di SMAN 9 Takalar Provinsi Sulawesi Selatan.

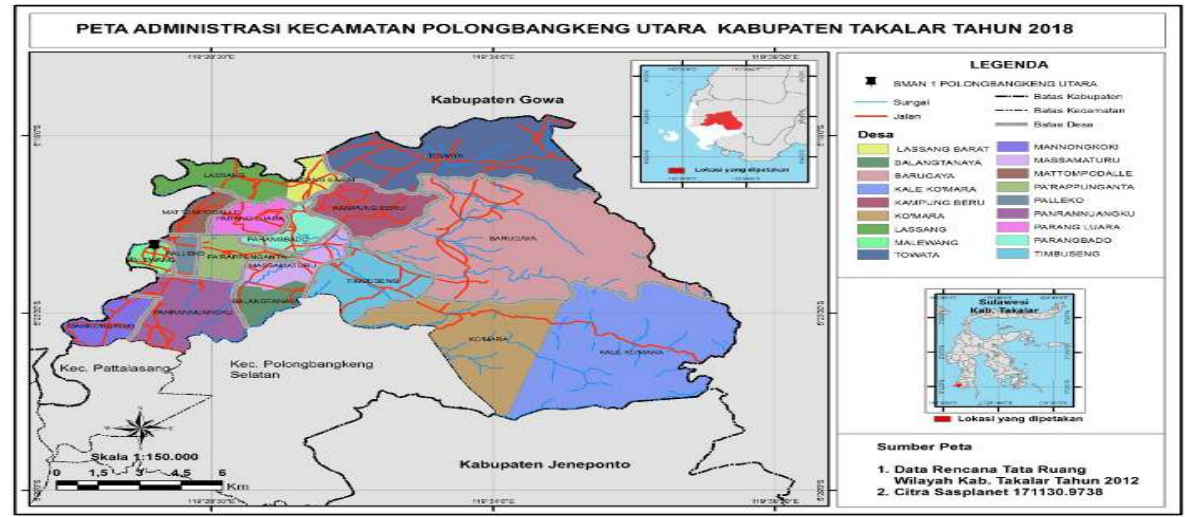

Gambar 1: Peta Administrasi Kecamatan Polongbangkeng Utara Kabupaten Takalar Sulawesi Selatan

Pengumpulan data dilakukan dengan observasi, wawancara, kajian literatur dan dokumentasi. Obsevasi merupakan metode pengumpulan data dimana peneliti mengamati dan berupaya mengetahui fenomena yang terjadi terhadap objek penelitian. Wawancara dilakukan secara terstruktur kepada informan. Kajian literatur merupakan suatu teknik pengumpulan data dari berbagai sumber seperti jurnal, buku dokumentasi, dan internet. Dokumentasi dilakukan dilakukan dengan mengumpulkan data tentang dinamika pembelajaran geografi dan faktor-faktor pendukung kualitas pembelajaran geografi. Teknik analisis data dilakukan melalui:

- Pengumpulan data yaitu pengumpulan data-data yang diperlukan melalui observasi, wawancara, dokumentasi dan kajian pustaka.

- Reduksi data (pemilihan data), yaitu memilih data-data yang yang relevan sesuai dengan tujuan penelitian.

- Display Data (penyajian data), yaitu menyajikan data dalam bentuk laporan secara sistematik,mudah dibaca dan mudah dipahami.

- Penarikan Kesimpulan/verifikasi, berdasarkan data relevan, kemudian ditarik satu kesimpulan untuk memperoleh hasil akhir penelitian.

Tehnis analisis data didasarkan pada teori Miles (1994): 
CENDEKIA, Vol. 12. No. 2 Oktober 2018

p-ISSN: 1978-2098; e-ISSN: 2407-8557

Http://cendekia.pusatbahasa.or.id; Email: cendekiaoslo@gmail.com

Center of Language and Cultural Studies, Surakarta, Indonesia

Syarif, Erman. 2018. Dinamika Pembelajaran Geografi di SMAN 9 Takalar Sulawesi Selatan.

Cendekia (2018), 12(2): 75-84. DOI: 10.30957/Cendekia.v12i2.519

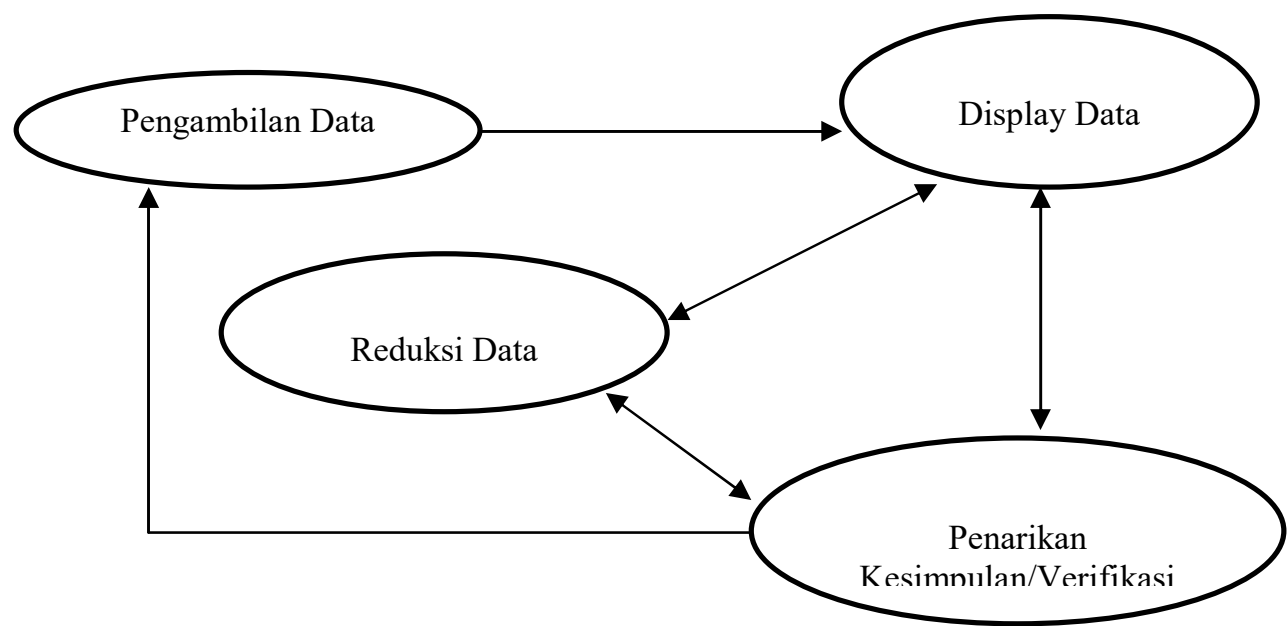

Gambar: 1. Teknik Analisis Data

\section{HASIL}

Hasil utama penelitian ini diperoleh dari informasi berdasarkan keterangan informan. Matriks informasi yang diperoleh dari informan dapat dilihat pada tabel 3 .

\section{Tabel 3 Matriks Informasi yang diperoleh dari Informan}

\begin{tabular}{|c|c|c|c|}
\hline No. & Informan & Informasi yang diberikan & Domain yang ditemukan \\
\hline 1 & $\begin{array}{l}\text { Peserta didik } \\
\text { (Rahmawati) }\end{array}$ & $\begin{array}{l}\text { Kondisi proses pembelajaran di kelas kurang melibatkan peserta didik } \\
\text { dalam belajar secara aktif dan optimal. Peserta didik cenderung pasif, } \\
\text { duduk, mendengarkan ceramah dari guru secara monoton dan bagi saya } \\
\text { metode pembelajaran yang diterapkan oleh guru amatlah membosankan. }\end{array}$ & $\begin{array}{l}\text { Dinamika pembelajaran } \\
\text { geografi di SMAN } 9 \\
\text { Takalar }\end{array}$ \\
\hline 2 & $\begin{array}{l}\text { Peserta didik } \\
\text { (Musakkir) }\end{array}$ & $\begin{array}{l}\text { Guru mata pelajaran geografi kurang memfasilitasi dan memotivasi } \\
\text { peserta didik dalam belajar melalui desain model-model pembelajaran } \\
\text { yang berinovasi, yang dapat mendorong para siswa agar lebih aktif dalam } \\
\text { proses pembelajaran. }\end{array}$ & $\begin{array}{l}\text { Dinamika pembelajaran } \\
\text { geografi di SMAN } 9 \\
\text { Kabupaten Takalar }\end{array}$ \\
\hline 3 & $\begin{array}{l}\text { Peserta didik } \\
\text { (Amran) }\end{array}$ & $\begin{array}{l}\text { Media pembelajaran yang digunakan oleh guru geografi tidak menarik dan } \\
\text { sumber belajar hanya terpaku pada buku teks yang ada. Dan juga dalam } \\
\text { proses pembelajaran kebanyakan guru selalu memberikan Lembar kerja } \\
\text { peserta didik dan mengembalikan tanpa memeriksa apa yang telah kami } \\
\text { kerjakan. }\end{array}$ & $\begin{array}{l}\text { Dinamika pembelajaran } \\
\text { geografi di SMAN } 9 \\
\text { Takalar }\end{array}$ \\
\hline 4 & $\begin{array}{l}\text { Guru Mata } \\
\text { Pelajaran } \\
\text { Geografi } \\
\text { Kelas X }\end{array}$ & $\begin{array}{l}\text { Jumlah peserta didik yang terlalu banyak dalam satu kelas (45 orang) } \\
\text { sehingga kita sebagai guru amatlah kesulitan di dalam hal memaksimalkan } \\
\text { proses pembelajaran apalagi di sekolah kami kurang di dukung oleh media } \\
\text { LCD Proyektor, dimana mata pelajaran geografi identik dengan fenomena } \\
\text { yang harus di perkenalkan dan diinformasikan kepada peserta didik. }\end{array}$ & $\begin{array}{l}\text { Dinamika pembelajaran } \\
\text { geografi di SMAN } 9 \\
\text { Takalar }\end{array}$ \\
\hline 5 & $\begin{array}{l}\text { Guru Mata } \\
\text { Pelajaran } \\
\text { Geografi } \\
\text { Kelas X }\end{array}$ & $\begin{array}{l}\text { Peserta didik memandang geografi sebagaimana pelajaran yang kurang } \\
\text { menarik, tidak menyenangkan, monoton, hafalan, dan tidak penting. } \\
\text { Akibatnya, hasil UN mata pelajaran geografi tergolong rendah dan } \\
\text { lebihdari } 65 \% \text { kompetensi tidak dikuasai oleh pesertadidik }\end{array}$ & $\begin{array}{l}\text { Dinamika pembelajaran } \\
\text { geografi di SMAN } 9 \\
\text { Takalar }\end{array}$ \\
\hline 6 & $\begin{array}{l}\text { Guru Mata } \\
\text { Pelajaran } \\
\text { Geografi } \\
\text { Kelas XI }\end{array}$ & $\begin{array}{l}\text { Kurangnya dukungan dari orang tua terhadap keaktifan belajara } \\
\text { dikarenakan kesibukan orang tua anak yang mayoritas bekerja sehari-hari } \\
\text { sebagai petani, sangat sibuk mengurusi pekerjaan mereka, dan kembali } \\
\text { kerumah pada waktu senja dalam kondisi kelelahan sehingga tidak } \\
\text { memungkinkan untuk mendukung anak secara intensif dalam } \\
\text { melaksanakan aktivitas belajar di rumah. }\end{array}$ & $\begin{array}{l}\text { Dinamika pembelajaran } \\
\text { geografi di SMAN } 9 \\
\text { Takalar }\end{array}$ \\
\hline
\end{tabular}

Sumber: Hasil wawancara informan (tanggal 14 Maret 2018) 
CENDEKIA, Vol. 12. No. 2 Oktober 2018

p-ISSN: 1978-2098; e-ISSN: 2407-8557

Http://cendekia.pusatbahasa.or.id; Email: cendekiaoslo@gmail.com

Center of Language and Cultural Studies, Surakarta, Indonesia

Syarif, Erman. 2018. Dinamika Pembelajaran Geografi di SMAN 9 Takalar Sulawesi Selatan.

Cendekia (2018), 12(2): 75-84. DOI: 10.30957/Cendekia.v12i2.519

Tabel 3 Matriks Informasi yang diperoleh dari Informan (sambungan)

\begin{tabular}{|c|c|c|c|}
\hline No. & Informan & Informasi yang diberikan & Domain yang ditemukan \\
\hline 7 & $\begin{array}{l}\text { Kepala } \\
\text { Sekolah }\end{array}$ & $\begin{array}{l}\text { Kompetensi pedagogik dan kompetensi professional sangat mempengaruhi } \\
\text { hasil belajar dari peserta didik itu sendiri. }\end{array}$ & $\begin{array}{l}\text { Dinamika pembelajaran } \\
\text { geografi di SMAN } 9 \\
\text { Takalar }\end{array}$ \\
\hline 8 & $\begin{array}{l}\text { Wakasek } \\
\text { Kurikulum }\end{array}$ & $\begin{array}{l}\text { Pendidikan geografi diharapkan dapat mengembangkan pemahaman } \\
\text { pesertadidik mengenai organisasi spasial,masyarakat, tempat-tempat dan } \\
\text { lingkungan di muka bumi. Peserta didik sejatinya didorong untuk dapat } \\
\text { memahami segala macam proses yang membentuk berbagai pola muka } \\
\text { bumi, karakteristik dan distribusi spasial, yang akhirnya yang tidak } \\
\text { terpisahkan dari sistem lingkungan. }\end{array}$ & $\begin{array}{l}\text { Dinamika pembelajaran } \\
\text { geografi di SMAN } 9 \\
\text { Takalar }\end{array}$ \\
\hline 9 & Wali Kelas & $\begin{array}{l}\text { Pembelajaran yang masih berpusat pada guru sudah saatnya beralih } \\
\text { menjadi berpusat pada siswa. }\end{array}$ & $\begin{array}{l}\text { Dinamika pembelajaran } \\
\text { geografi di SMAN } 9 \\
\text { Takalar }\end{array}$ \\
\hline 10 & $\begin{array}{l}\text { Guru Mata } \\
\text { Pelajaran } \\
\text { Geografi }\end{array}$ & $\begin{array}{l}\text { Kualifikasi guru tidak sesuai dengan bidang ajarnya, oleh karena itu yang } \\
\text { mengajar geografi sebaiknya adalah alumni dari geografi. }\end{array}$ & $\begin{array}{l}\text { Faktor-faktor pendukung } \\
\text { kualitas pembelajaran } \\
\text { geografi di SMAN } 9 \\
\text { Takalar }\end{array}$ \\
\hline 11 & $\begin{array}{l}\text { Guru Mata } \\
\text { Pelajaran } \\
\text { Geografi }\end{array}$ & $\begin{array}{l}\text { adanya sikap siswa yang positif terhadap pelajaran geografi,memiliki } \\
\text { motivasi yang cukup tinggi untuk berprestasi dalam mata pelajaran } \\
\text { geografi, sumber pembelajaran yang cukup memadai, dan iklim kelas } \\
\text { yang mendukung proses pembelajaran geografi. }\end{array}$ & $\begin{array}{l}\text { Faktor-faktor pendukung } \\
\text { kualitas pembelajaran } \\
\text { geografi di SMAN } 9 \\
\text { Takalar }\end{array}$ \\
\hline 12 & $\begin{array}{l}\text { Kepala } \\
\text { Sekolah }\end{array}$ & $\begin{array}{l}\text { Gurudan peserta didik harus berkolaborasi demi pencapaian peningkatan } \\
\text { hasil belajar serta menanamkan prinsip bahwa guru yang berhasil harus } \\
\text { mempunyai sikap dan ketrampilan yang mendorong peserta didik aktif } \\
\text { untuk berfikir dan mampu memecahkan masalah, serta menguasai } \\
\text { sejumlah ketrampilan dalam dunia pendidikan. }\end{array}$ & $\begin{array}{l}\text { Faktor-faktor pendukung } \\
\text { kualitas pembelajaran } \\
\text { geografi di SMA } 9 \text { Takalar }\end{array}$ \\
\hline 13 & $\begin{array}{l}\text { Wakasek } \\
\text { Kurikulum }\end{array}$ & $\begin{array}{l}\text { Faktor pendukung kualitas pembelajaran geografi di SMA } 9 \text { Takalaryakni } \\
\text { 1) kualitas guru itu sendiri, peningkatan kesadaran bagi para guru untuk } \\
\text { memiliki laptop/netbook, 2) perlunya memperbanyak sumber bacaan dan } \\
\text { video pembelajaran tentang model-model pembelajaran. }\end{array}$ & $\begin{array}{l}\text { Faktor-faktor pendukung } \\
\text { kualitas pembelajaran } \\
\text { geografi di SMAN } 9 \\
\text { Takalar }\end{array}$ \\
\hline 14 & Wali Kelas & $\begin{array}{l}\text { Seharusnya guru mampu memahami karakteristik dan keinginan peserta } \\
\text { didiknya dengan menggunakan metode yang variatif yang mampu } \\
\text { menggugah kreatifitas peserta didik sehingga termotivasi untukbelajar. }\end{array}$ & $\begin{array}{l}\text { Faktor-faktor pendukung } \\
\text { kualitas pembelajaran } \\
\text { geografi di SMAN } 9 \\
\text { Takalar }\end{array}$ \\
\hline 15 & $\begin{array}{l}\text { Guru Mata } \\
\text { Pelajaran } \\
\text { Lain }\end{array}$ & $\begin{array}{l}\text { Perlunya diadakan pelatihan seperti MGMP secara rutin. Dan penyediaan } \\
\text { sarana dan prasarana sekolah untuk menunjang proses pembelajaran } \\
\text { secara maksimal. }\end{array}$ & $\begin{array}{l}\text { Faktor-faktor pendukung } \\
\text { kualitas pembelajaran } \\
\text { geografi di SMAN } 9 \\
\text { Takalar }\end{array}$ \\
\hline
\end{tabular}

Sumber: Hasil wawancara informan (tanggal 14 Maret 2018)

Keberhasilan tujuan pendidikan, sangat ditentukan oleh implementasinya. Dinamika pembelajaran geografi di SMAN 9 Takalar sudah berlangsung baik. Hal tersebut dapat dilihat dari kualitas proses dan hasil pembelajaran. Sistem penilaian yang dilaksanakan oleh guru geografi juga sudah mencakup penilaian proses dan produk pembelajaran. Keberhasilan dalam pembelajaran dipengaruhi oleh beberapa faktor. Faktor-faktor pendukung kualitas pembelajaran geografi di SMAN 9 Takalar yakni: sarana dan prasarana pembelajaran, kualitas guru, aktivitas guru dan siswa dalam proses pembelajaran, dan siswa yang berkualitas (cerdas, mempunyai motivasi belajar yang tinggi dan mempunyai sikap yang positif dalam belajar). Kualitas pembelajaran merupakan ukuran yang menunjukkan seberapa tinggi kualitas interaksi antara guru dengan siswa dalam proses pembelajaran khususnya dalam pembelajaran geografi. Oleh karena itu, keberhasilan proses pembelajaran sangat tergantung pada: guru, siswa, sarana pembelajaran, lingkungan kelas, dan budaya kelas. Semua indikator tersebut harus saling mendukung dalam sebuah sistem kegiatan pembelajaran yang berkualitas. 
CENDEKIA, Vol. 12. No. 2 Oktober 2018

p-ISSN: 1978-2098; e-ISSN: 2407-8557

Http://cendekia.pusatbahasa.or.id; Email: cendekiaoslo@gmail.com

Center of Language and Cultural Studies, Surakarta, Indonesia

Syarif, Erman. 2018. Dinamika Pembelajaran Geografi di SMAN 9 Takalar Sulawesi Selatan.

Cendekia (2018), 12(2): 75-84. DOI: 10.30957/Cendekia.v12i2.519

\section{BAHASAN}

\section{1. Dinamika Pembelajaran Geografi di SMAN 9 Takalar}

Berdasarkan hasil temuan dapat disimpulkan bahwa: 1) kondisi proses pembelajaran di kelas kurang melibatkan peserta didik dalam belajar secara aktif dan optimal, 2) Guru mata pelajaran geografi kurang memfasilitasi dan memotivasi peserta didik dalam belajar melalui desain model-model pembelajaran yang berinovasi, 3) media pembelajaran yang digunakan oleh guru geografi tidak menarik dan sumber belajar hanya terpaku pada buku teks yang ada, dan 4) pembelajaran yang diterapkan oleh guru masih menggunakan pendekatan terpusat pada guru. Henson (1999) mengungkapkan bahwa peserta didik dalam pembelajaran harus diarahkan untuk menemukan konsep yang sesuai dengan pemahamannya, kenyaman dalam belajar, tertarik dengan materi dan merangsang kreativitas peserta didik.

Menurut Borko (2004) pengembangan profesional guru sangat penting sebagai upaya peningkatan kualitas pembelajaran. Lebih lanjut Hughes (2005) menjelaskan bahwa guru harus menguasai dan mengembangkan teknologi dalam proses pembelajaran. Sementara Maryani (2006) mengungkapkan ada beberapa faktor penyebab tidak menariknya pembelajaran geografi di sekolah karena pembelajaran geografi seringkali terjebak pada aspek kognitif tingkat rendah, dan pembelajaran geografi kurang aplikabel dalam memecahkan masalah-masalah yang berkembang saat ini. Oleh karena itu motivasi belajar yang kuat dapat mendorong peserta didik untuk lebih giat dan rajin dalam belajar yang akan berdampak pada peningkatan hasil belajarnya khususnya dalam pembelajaran geografi.

\section{2. Faktor Pendukung Kualitas Pembelajaran Geografi di SMAN 9 Takalar}

Berdasarkan hasil temuan dapat disimpulkan bahwa: 1) Guru dan peserta didik harus berkolaborasi demi pencapaian peningkatan hasil belajar, 2) memperbanyak sumber bacaan dan video pembelajaran tentang model-model pembelajaran dan dikembangkan dalam pembelajaran geografi, dan 3) guru mampu memahami karakteristik peserta didiknya dengan menggunakan model pembelajaran yang variatif dan inovatif sehingga mampu merangsang kreatifitas dan motivasi peserta didik dalam proses pembelajaran.Senada dengan itu Concannon (2005) mengungkapkan bahwa penggunaan teknologi dapat meningkatkan kualitas pembelajaran. Lebih lanjut Resta (2007) penerapan teknologi dalam pembelajaran sangat membantu keberhasilan pembelajaran dan dapat merangsang interaksi sosial peserta didik.Sementara Syarif (2018) menekankan pentingnya pengintegrasian nilai-nilai pendidikan karakter dalam proses pembelajaran geografidengan tujuan membentuk karakter peserta didik. Oleh karena itu, peningktan kualitas pembelajaran khususnya mata pelajaran geografi dipengaruhi oleh beberapa faktor.

\section{SIMPULAN}

Penelitian ini bertujuan untuk mengidentifikasi dinamika pembelajaran geografi dan mendeskripsikan faktor-faktor apa yang menjadi pendukung kualitas pembelajaran geografidi SMAN 9 Takalar. Hasil penelitian disimpulkan sebagai berikut. 
CENDEKIA, Vol. 12. No. 2 Oktober 2018

p-ISSN: 1978-2098; e-ISSN: 2407-8557

Http://cendekia.pusatbahasa.or.id; Email: cendekiaoslo@gmail.com

Center of Language and Cultural Studies, Surakarta, Indonesia

Syarif, Erman. 2018. Dinamika Pembelajaran Geografi di SMAN 9 Takalar Sulawesi Selatan.

Cendekia (2018), 12(2): 75-84. DOI: 10.30957/Cendekia.v12i2.519

Secara umum dinamika pembelajaran geografi di SMAN 9 Takalar yakni 1) ) kurang melibatkan peserta didik dalam proses pembelajaran, 2) Guru mata pelajaran geografi kurang memfasilitasi dan memotivasi peserta didik dalam proses pembelajaran, 3) guru kurang mengembangkan model-model pembelajaran yang inovatif, dan 4) pendekatan yang digunakan oleh guru dalam pembelajaran masih menggunakan pendekatan terpusat pada guru. Adapun faktor-faktor pendukung kualitas pembelajaran geografi yakni: 1) Guru dan peserta didik harus berkolaborasi demi pencapaian peningkatan hasil belajar, 2) memperbanyak sumber bacaan dan video pembelajaran tentang model-model pembelajaran dan dikembangkan dalam pembelajaran geografi, dan 3) guru mampu memahami karakteristik peserta didiknya dengan menggunakan model pembelajaran yang variatif dan inovatif.

Hasil penelitian ini menunjukkan kondisi pembelajaran kurang melibatkan peserta didik dalam belajar secara aktif dan optimal, dimana guru mata pelajaran geografi kurang memfasilitasi dan memotivasi peserta didik dalam belajar melalui desain model-model pembelajaran yang berinovasi, yang dapat mendorong para siswa agar lebihaktif dalam proses pembelajaran. Sedangkan faktor-faktor pendukung kualitas pembelajaran yakni respon siswa yang positif terhadap mata pelajaran geografi, memiliki motivasi yang cukup tinggi untuk kualitas dan hasil belajar dalam mata pelajaran geografi, sumber pembelajaran yang cukup memadai, dan iklim kelas yang sangat mendukung proses pembelajaran geografi di kelas. Dengan demikian hasil penelitian ini diharapkan: 1) menjadi inspirasi dan motivasi untuk lebih meningkatkan profesionalisme guru, 2) sebagai landasan bagi kepala sekolah dan guru untuk senantiasa memperhatikan faktor-faktor pendukung terwujudnya kualitas pembelajaran yang optimal,dan 3) menjadi referensi dalam mengambil kebijakan terkait peningkatan mutu pendidikan di Indonesia khususnya di Sulawesi Selatan.

\section{DAFTAR PUSTAKA}

Ali, M. 2009. Pendidikan Untuk Pembangunan Nasional Menuju Bangsa Indonesia yang Mandiri dan Berdaya Saing Tinggi. Bandung: PT Imperial Bakti Utama

Barnawi dan Arifin. 2012. Strategi dan Kebijakan Pembelajaran Pendidikan Karakter. Jogjakarta: Ar-Ruzz Media Group.

Borko, H. 2004. Professional development and teacher learning: Mapping the terrain. Educational researcher, 33(8):3-15.

Brooks, J.G \& Brooks, M.G. 1999. In Search of Understanding : The Case Constructivist Clasroom. Virginia: Association of Supervision and Curriculum Development.

Concannon, F. F. \& Campbell, M. 2005. What campus-based students think about the quality and benefits of e-learning. British Journal of Education Technology. 36(3), pp. 501-512.

Dimyati \& Mudjiono. 2013. Belajar Dan Pembelajaran. Jakarta: Rineka Cipta.

Fitri, A.Z. 2012. Pendidikan Karakter Berbasis Nilai \& Etika Di Sekolah. Jogjakarta : Ar-Ruzz Media. 
CENDEKIA, Vol. 12. No. 2 Oktober 2018

p-ISSN: 1978-2098; e-ISSN: 2407-8557

Http://cendekia.pusatbahasa.or.id; Email: cendekiaoslo@gmail.com

Center of Language and Cultural Studies, Surakarta, Indonesia

Syarif, Erman. 2018. Dinamika Pembelajaran Geografi di SMAN 9 Takalar Sulawesi Selatan.

Cendekia (2018), 12(2): 75-84. DOI: 10.30957/Cendekia.v12i2.519

Gufran, G., Amat M. \& Putro, S.C. 2012. Pelaksanaan PLPG sebagai wahana pengembangan dan audit kompetensi dalam sertifikasi guru bidang kejuruan. Teknologi dan Kejuruan 34.2 (online).

Hamruni. 2011. Strategi Pembelajaran. Insan Madani. Yogyakarta.

Hamzah. B. U. 2006.Orientasi Baru dalam Psikologi Pembelajaran.Jakarta: PT Bumi Aksara.

Hari,A. 2011. Pemetaan Kompetensi, Sikap, Tanggung Jawab, Jumlah Jam Mengelola Pembelajaran di SMK se-Malang Raya. Tesis. Malang: Pps Universitas Negeri Malang.

Henson, K. T., \& Eller, B. F. 1999. Educational Psychology for Effective Teaching. California: Wadsworth Publishing Company.

Hughes, J. 2005. The role of teacher knowledge and learning experiences in forming technology-integrated pedagogy. Journal of technology and teacher education, 13(2), 277.

Kemendikbud. 2013. Kerangka Dasar Kurikulum 2013. Jakarta: Kementerian Pendidikan dan Kebudayaan Direktorat Jenderal Pendidikan Dasar.

Maryani, E. 2006. Geografi dalam Perspektif Keilmuan dan Pendidikan di Persekolahan. Dimuat dalam Buku "Ilmu Pendidikan". Karangan Mohamad Ali (ed), Bandung.

Marzano, R.J., Pickering, D., \& McTinghe. 1993. Assesing Student Outcomes: Performance Assesment Using the Dimension of Learning Models. Alexandria: ASCD.

Miles, M.B \& Huberman A.M. 1994. Analisis Data Kualitatif. Jakarta: Penerbit Universitas Indonesia.

Moore, K.D. 2005. Effective Instructional Strategies from Theory to Practice. California, Thousand Oaks: Sage Publication.

Mulyasa, E. 2007. Menjadi Guru Profesional menciptakan Pembelajaran Kreatif dan Menyenangkan. Bandung: Rosdakarya.

Resta, P., \& Laferrière, T. 2007. Technology in support of collaborative learning. Educational Psychology Review, 19(1), 65-83.

Slameto. 2013. Belajar dan Faktor-Faktor yang Mempengaruhinya. Jakarta: Rineka Cipta.

Slavin, R.E. 2006. Cooperative Learning: Theory, Research and Practice. Boston : Allyn and Bacon.

Surakhmad, Winarno. 2000. Metodologi Pengajaran Nasional. Jakarta: UHAMKA.

Syarif, E., Sumarmi, S., Fatchan, A. and Astina, I.K., 2016. Integrasi Nilai Budaya Etnis Bugis Makassar Dalam Proses Pembelajaran Sebagai Salah Satu Strategi Menghadapi Era Masyarakat Ekonomi Asean (MEA). Jurnal Teori dan Praksis Pembelajaran IPS, 1(1), pp.13-21.

Syarif, E., Hasriyanti, H., Fatchan, A., Astina, I.K. and Sumarmi, S., 2016. Conservation Values Of Local Wisdom Traditional Ceremony Rambu Solo Toraja's Tribe South Sulawesi As Efforts The Establishment of Character Education. EFL JOURNAL, 1(1), pp.17-23. 
CENDEKIA, Vol. 12. No. 2 Oktober 2018

p-ISSN: 1978-2098; e-ISSN: 2407-8557

Http://cendekia.pusatbahasa.or.id; Email: cendekiaoslo@gmail.com

Center of Language and Cultural Studies, Surakarta, Indonesia

Syarif, Erman. 2018. Dinamika Pembelajaran Geografi di SMAN 9 Takalar Sulawesi Selatan. Cendekia (2018), 12(2): 75-84. DOI: 10.30957/Cendekia.v12i2.519

Syarif, E. 2018. The Role of Geography Learning in Developing Conservation Characterof Participant in SMA Negeri 9 Gowa. UNM Geographic Journal, 1(2):111-120.

Trianto. 2009.Model-Model Pembelajaran Inovatif-Progresif. Surabaya: Prenada Media Group.

Zaini, Hisyam. dkk. 2007. Strategi Pembelajaran Aktif. Pustaka Insan Madani. Yogyakarta. 